\title{
Formation of Critical Thinking Among Students Majoring in Teaching by Adopting Innovative Approach at University
}

\author{
Galina Vasilievna Akhmetzhanova \\ Togliatti State University \\ Togliatti, Russia \\ g.v.ahmet@mail.ru
}

\author{
Tatiana Vitalievna Emelyanova \\ Togliatti State University \\ Togliatti, Russia
}

\author{
Lyudmila Aleksandrovna Sundeeva \\ Togliatti State University \\ Togliatti, Russia
}

\begin{abstract}
This article considers the innovative approach of a higher school lecturer intended to foster critical thinking, highlights the need and importance of this type of thinking for future teachers, analyses different definitions of critical thinking, and examines its structure and components. The article presents techniques that can be used to instill active thinking patterns in students, describes methods of question formulation in the process of education, methods of critical thinking development in the process of speaking, as well as methods of objective setting. Close attention is paid to the method of question formulation in the frame of critical thinking development: simple, clarifying, explaining, creative, evaluative, and practical questions. The article describes the process and outcomes of the experiment in the development of the reflexive quality of critical thinking; indicated key aspects of methods that were used as diagnostic tools to evaluate this introspective level. It is noted that the experimental work showed positive results and proved the effectiveness of the above-mentioned technology in fostering critical thinking among students majoring in teaching by means of innovative approach at university.
\end{abstract}

Keywords-critical thinking, innovative activities, higher education, interpretation and evaluation of information, thinking strategies, reflection

\section{INTRODUCTION}

The process of modern society development is stimulated by innovations - ideas, products and processes that help create new industries and jobs, stimulate economic growth and contribute to positive results in upbringing and education on the national level.

Long-term education process with an outlook on the future should be based on two inseparable principles: the ability to quickly find one's way around in the rapidly growing information flow and the ability to find the information one needs and then to understand and utilize this information (D.F. Halpern, S.G. Nummedal, N.R. Hanson) [1, 2].
Productive, goal-oriented and conscious innovative thinking lies in the very heart of an effective teaching process. This type of thinking enables present day teachers and teachers-to-be to gain deeper understanding of the teaching process prospects, effectively solve problems, find, evaluate and utilize relevant information, generate new ideas. Aside from that, progressive development and use of innovative learning strategies can improve the educational and professional motivation of students.

\section{METHODS}

Intellectual activity, its innovative type including, is based on critical thinking which provides the ability to identify or develop arguments, use proof, make justified conclusions and use information for solving problems.

Psychological and pedagogical literature, for example, defines critical thinking as reasonable reflective thinking focused on deciding what to believe or do (R.H. Ennis) [3], as a skill enabling a person to effectively confront challenges of the XXI century, more deeply understand what we study and do (V. Miu-ChiLun, R. Fischer, C. Ward) [4], as an ability and desire to reflect upon different statements and come up with objective judgments based on well-grounded proof (C. Tavris, C. Wade) [5]. The critical thinking is also defined as a process of analysis and evaluation of statements and activities in order to determine their feasibility and implementability (R. Paul and L. Elder) [6], this process is logical and introspective, has a clear moral basis (M. Bermingham) [7], is ruled by clear intellectual standards (G. Bassham, W. Irwin, H. Nardone, J. Wallace) [8].

Russian scientists have also contributed substantially to the study of critical thinking. For example, M.V. Klarin [9] distinguishes such specific characteristics of critical thinking as rationality, reflexivity, focusing on detecting reliable objects and phenomena. I.O. Zagashev [10] also considers reflexivity as one of the necessary characteristics of critical thinking. 
It's worth mentioning that critical thinking is a general term encompassing a wide variety of cognitive skills and intellectual dispositions needed to effectively identify, analyse and evaluate arguments and true statements and to discover and overcome personal prejudice. It is the ability to formulate and present convincing reasons in support of conclusions and to make reasonable, smart decisions about an upcoming activity.

The process of critical thinking development is now ongoing at all levels of education; however, a significant role in this process is assigned to universities. Mission of higher education institutions and education they provide is not only to make their graduates informed, but also to bring up people able to think critically and apply analytical approach to social problematics treatment.

Dedicated courses on critical thinking skills development are now introduced to the educational programs of most European universities. Studies conducted at the University of Leeds, for instance, have shown the need to form critical thinking, but students are often not ready for this. Based on this, the CriticalThinkingSkills course, which is part of the academic skills courses portfolio, has been developed for students of all majors (https://www.futurelearn.com/courses/critical-thinking-atuniversity).

Some Russian universities are also turning to the ideas of forming critical thinking nowadays. For example, the "Critical Thinking" discipline has been introduced to the educational program of the National Research University "Higher School of Economics" and Volgograd State University. Pedagogical universities cover this knowledge area in such programs as "Technology of the Formation of Critical Thinking", the content of which is focused mainly on presenting to the future teachers critical thinking techniques that they will be able to use in their work with students when they graduate, but while attending university they are not trained to develop such skill in themselves.

At the same time, the technology of the formation of critical thinking as an effective innovative tool that combines working practices by types of educational activity is of great interest to the pedagogical and scientific community. The components of this structure include the independence of thought, curiosity, ability of problem formulating and finding ways to solve it, careful planning of decision-making process, free and justified expression of one's opinion [11].

S. Brookfield distinguishes four components of critical thinking:

1. Identification and challenging an assumption.

2. Challenging the importance of a context.

3. Imagining and exploring an alternative.

4. Reflective scepticism [12].

B.V. Sergeeva and V.A. Oganesyan [13] have developed a four-component structure of critical thinking which includes a cognitive, analytical (introspective), personal and activityrelated component.
Despite different structures of the above-mentioned approaches, the essence of critical thinking as a complicated comprehensive process in which a person collects, processes, evaluates and applies information, is the same [14].

The structure of the analysed comprehensive process includes different levels of the formation of critical thinking. Our research is focused on the study of the reflexive component of the critical thinking structure. This selection was based on the fact that reflexivity involves successful implementation of the actions of comparison, analysis, synthesis, abstraction, generalization and specialization.

\section{RESULTS AND DISCUSSION}

During 2018/2019 academic year, Togliatti State University conducted an experiment on the development of reflexivity of critical thinking based on the similarly named technology. The subjects were bachelors of 1-4 courses (61 people) with the major in "Psychology and Pedagogy of Elementary Education".

The following methods were included in the diagnostic tools:

- determination of reflexivity of thinking

(O.S. Anisimov) [15];

- discovering the reflexivity level (A.V. Karpov, V.V. Ponomaryova) [16].

For example, indicators specified by O.S. Anisimov (reflexivity, collectivity, self-criticism) were discovered by means of questions, the answers to which allowed finding a way to solve pedagogical problems. This method gives quantitative data in relative units on the level of expression of reflection in pedagogical activity and allows evaluating the level of demonstration of personal qualities of the subject associated with reflexivity. When analyzing the answers, points were given in relative units depending on the significance of the possible answer. The reflection level was determined by adding the given points. The results showed that $7 \%$ of the students have a high level of development of reflexivity of thinking, $35 \%$ have a medium level, while $58 \%$ have a low level of reflexivity. Students who have a medium or low level of this type of thinking are not able to make an adequate evaluation of their actions and the behavior of others, are not ready to admit their mistakes, hardly make compromises.

The experiment accuracy was achieved by the use of a backup diagnostic method (A.V. Karpov, V.V. Ponomaryova), which allowed obtaining the following results: $4 \%$ of the subjects have a high level of reflexivity. These students are able to analyse their actions and actions of others, establish causes and consequences, define details in the work, engage in planning and predict possible consequences. $39 \%$ of the respondents have a medium level of reflexivity, $51 \%$ of the subjects have a low level of reflexivity. Such students are especially bad at regulating their behavior. Fig. 1 shows comparison of results of diagnostics of the reflexive component of critical thinking developed by students according to two above-described methods. 
The obtained results show that the level of the reflexive component of critical thinking developed by future teachers is insufficient.

At the second stage of the experiment, the basic technique of development of critical thinking (Charles Temple, Jeannie L. Steele, Kurtis S. Meredith, 2008) [17] was used in order to increase the level of critical thinking developed by future teachers; according to this technique, the planning and implementation of the teaching process shall consist of three stages: challenge, comprehension and reflection. Each stage has different techniques ensuring the development of active mental activity by students.

The following methods were used during the experiment:

- methods of question formulation in the teaching process, because the formulation of a correct question at the very beginning of work determines the success of getting the correct answer to a large extent;

- methods of development of critical thinking in speech activity. Despite the fact that thinking is an individual and independent process, critical thinking occurs in disputes, causing the need for students to develop communicative skills;

- methods of problem formulation. The formation of critical thinking involves encouraging a creative approach and formulating problems that cannot be solved in the traditional way.

During training lessons of future teachers, the following techniques of critical thinking formation were used: the "Plus - Minus -Interesting" table, "Right/wrong statements", "Brainstorm", "Bold and delicate questions", etc.

One of the principles of this technique is using the experience of students as the basis. According to this, at the "Challenge" stage, the motive for development is created through known facts and events, by analyzing which the need for further thorough study of the topic arises.

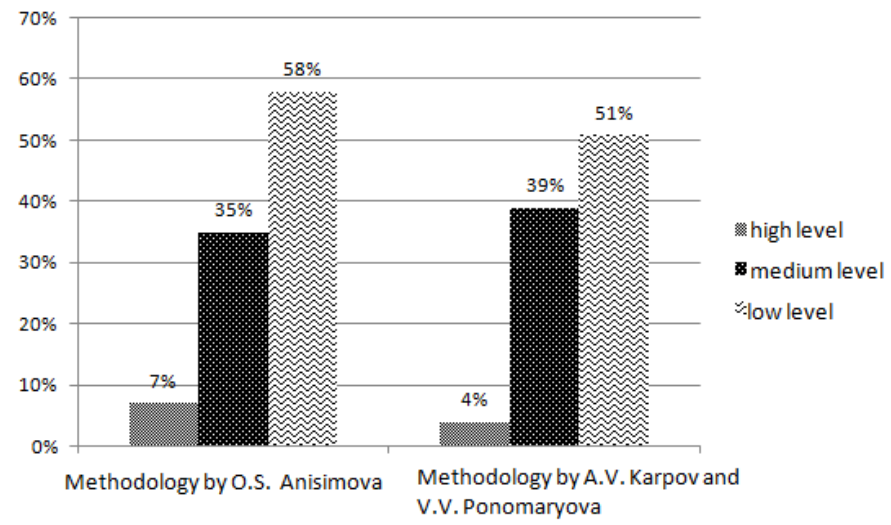

Fig. 1. Comparison of results of diagnostics of reflexivity developed by students at the initial research stage.

In the course of the experiment, special attention was paid to the method of formulating questions according to the system created by Benjamin Bloom [18]:
1. Simple questions (are used in tests, terminological tests, pass-fail exams, etc.). The answers to such questions involve actions of remembering and reproducing known information.

2. Clarifying questions are asked in order to obtain information lacking, but implied in the message ("If I understood you right, then ...?").

3. Explaining questions are aimed at establishing causeand-effect relations ("Why are visual teaching methods often used in the teaching process?", "Is it possible to use media resources at elementary school lessons?", etc.)

4. Creative questions. Their difference is the presence of the word "would" ("How would the world change if there was no class-lesson teaching system?", "How would the teaching and educational process develop if information technologies were not introduced to the educational environment?", etc.).

5. Evaluative questions are intended to create criteria and evaluate facts, phenomena and events ("Why does one child processes educational material quickly, while another does it slowly?", "Why do some children have logical thinking and others don't?", etc.).

6. Practical questions: "How to teach a child to defend their own opinion?", "How to enhance the exploratory activities of students?", "Is it possible to teach a child to generate new ideas?", etc.

The "Insert" technique involves marking the text used by students with special symbols: "V" — it is known to me (I know it), "+" — this information is new to me, "-" — I had another idea (it contradicts with what I knew), "?" — it is not clear to me (I need explanations, clarifications). The implementation of the technique takes two stages, which correspond to the stages of the basic technology of critical thinking formation. Normally, when implementing the technique, texts with a large amount of actual information are used.

The third control stage of the experiment included the repeated diagnostics of levels of reflexivity developed by students according to the method by O.S. Anisimov, which showed that the number of students with a high level of reflexivity increased by $9 \%$ (from $7 \%$ to $16 \%$ ). $55 \%$ of the future teachers who participated in the experiment showed a medium level of development of the studied component of critical thinking (the number increased by $20 \%$ of the initial level), while $29 \%$ of the students showed a low level of reflexivity (the number decreased by $29 \%$ of the initial level). Students are generally more willing to admit their mistakes; more adequately evaluate their own actions in any given situation, and show a tendency to seek for a compromise solution. The students subject the information obtained during the educational process to thorough fact analysis with the use of additional information from scientific sources

The diagnostics conducted according to a backup technique (A.V. Karpov, V.V. Ponomaryova) confirms the accuracy of the above-described results: $13 \%$ of the students have a high level of reflexivity (9\% increase). $39 \%$ of the respondents have a medium level of reflexivity $(21 \%$ increase), $37 \%$ of the participants have a low level of 
reflexivity (23\% decrease). Fig. 2 shows comparison of results of the final diagnostics of the reflexive component of critical thinking developed by students.

It shall be noted that the level of formation of critical thinking of the future teachers has increased by an average of $20 \%$ relative to the numbers obtained at the diagnostic stage.

\section{CONCLUSION}

The formation of critical thinking of future teachers is an expected process in the light of a wide variety of opportunities of higher schools for helping students to acquire information free from conformism and dogmatism. The methods analysed in this work are widely used when studying professional cycle of disciplines and, thus, contribute not only to the formation of critical thinking, but also to mastering the basics of teaching skills. And that in turn increases the skill level of future teachers due to the ability to form the teaching and educational process unconventionally, to adequately evaluate the results of activities, to stand up to attempts of suggestions, due to the desire to acquire new scientific knowledge and high social intelligence, the ability to correctly understand the actions of people.

At the same time, the analysis of students' performance of tasks allows to conclude about different levels of formation of critical thinking of students. On the one hand, they successfully managed the tasks of evaluating statements, were able to see cause-and-effect relations, which is necessary, for example, for a teacher to accurately evaluate the effectiveness of the introduction of a particular innovative technology to the teaching process. On the other hand, challenges were presented by tasks that required factual confirmation or denial of the correctness of well-established approaches to the organization of the teaching process.

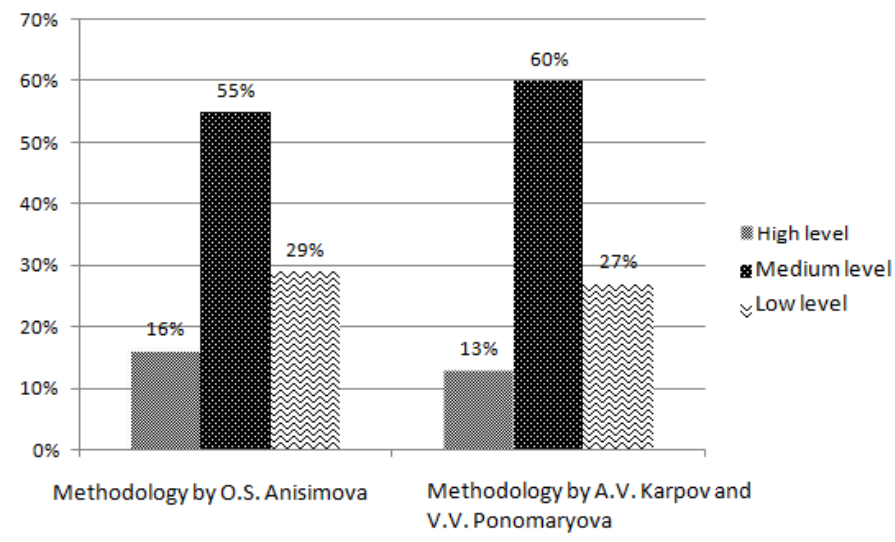

Fig. 2. Comparison of results of diagnostics of reflexivity developed by students at the initial research stage.
Thus, innovative activity of a higher school teacher must be focused not only on a deeper introduction of the technology of critical thinking to the teaching process, but also on the development of didactic tools for determining the level of formation of this type of thinking, as well as on designing specific ways of the organization of the teaching process and adequate evaluation of its effectiveness.

\section{References}

[1] D.F. Halpern, S. G. Nummedal, Psychologists teach critical thinking. Teaching of Psychology, vol. 22(1), 1995

[2] N.R. Hanson, Patterns of discovery. Cambridge, England: Cambridge University Press, 1958.

[3] R.H. Ennis, "Critical Thinking Dispositions: Their Nature and Assessability," Informal Logic, vol. 18(2), pp.165-182, 1966.

[4] V. Miu-Chi Lun, R. Fischer, C. Ward, Exploring cultural differences in critical thinking: Is it about my thinking style or the language I speak? Learning and Individual Differences, vol. 20, 2010, pp. 604-616.

[5] C.Tavris, C.Wade, Psychology in perspective. New York: HarperCollins, 1994.

[6] R. Paul, L. Elder. Critical Thinking: Concepts and Tools. Dillon Beach: Foundation for Critical Thinking Press, 2010.

[7] M. Bermingham, "Clearing up "Critical Thinking": Its Four Formidable Features," Creative Education, vol. 6, pp. 421-427, 2015.

[8] G. Bassham, W. Irwin, H. Nardone, J. Wallace, Critical thinking: a student's introduction (4th ed.). NewYork: McGraw-Hill, 2011

[9] M.V. Klarin, Innovation in the Global Pedagogy: Teaching based on Research, Game and Discussion. (Analysis of Foreign Practices) [Innovatsii v mirovoj pedagogike: obuchenie na osnove issledovaniya, igry i diskussii. (Analiz zarubezhnogo opyta)]. Riga: NPC "Experiment", 1995 , p. 176.

[10] I.O. Zagashev, S.I. Zair-Bek, I.V. Mushtavinskaya, Teaching Children to Think Critically [Uchim detey myslit' kriticheski]. SaintPetersburg:Peter, 2003, p. 67.

[11] P. Freire, Pedagogy of the Oppressed. Moscow: KoLibri, 2017, p. 152.

[12] S. Brookfield, Developing critical thinking: Challenging adults to explore alternative ways of thinking and acting. SanFrancisco, CA Jossey-Bass, 1987.

[13] B.V. Sergeeva, V.A. Oganesyan, "Theoretical Foundation of Critica Thinking of Elementary School Children [Teoreticheskie osnovy razvitiya kriticheskogo myshleniya mladshikh shkol'nikov]," Scientific Review.Pedagogical Sciences [Nauchnoe obozrenie. Pedagogicheskie nauki], vol. 2, 2017

[14] L.A. Zhidova, Abilities of Critical Thinking as a Tool to Raise the Quality of Professional Training of Future Maths Teachers [Umeniya kriticheskogo myshleniya kak sredstvo povysheniya kachestva professional'noj podgotovki budushhikh uchitelej matematiki]," TSPU Bulletin [Vestnik TGPU], vol. 4, 2009.

[15] O.S. Anisimov, Methodological Culture of Teaching Activities and Thinking [Metodologicheskaya kul'tura pedagogicheskoj deyatel'nosti myshleniya]. Moscow: Ekonomika, 1991, p. 415

[16] A.V. Karpov, V.V. Ponomaryova, Psychology of Reflexive Contro Mechanisms [Psikhologiya refleksivnykh mekhanizmov upravleniya] Moscow: Institute of Psychology of RAS, 2000, p. 283. 